Article

\title{
Analysis and Identification of the Mechanism of Damage and Fracture of High-Filled Wood Fiber/Recycled High-Density Polyethylene Composites
}

\author{
Yong Guo ${ }^{1, * \mathbb{C}}$, Shiliu Zhu ${ }^{1}$, Yuxia Chen ${ }^{1}$ and Dagang $\mathrm{Li}^{2, *}$ \\ 1 School of Forestry and Landscape Architecture, Anhui Agricultural University, Hefei 230036, China; \\ zhuslwood@163.com (S.Z.); sheherose@163.com (Y.C.) \\ 2 College of Materials Science and Engineering, Nanjing Forestry University, Nanjing 210037, China \\ * Correspondence: fly828828@163.com (Y.G.); njfuldg@163.com (D.L.); Tel.: +86-138-5691-8979 (Y.G.); \\ +86-139-1298-1251 (D.L.)
}

Received: 24 December 2018; Accepted: 14 January 2019; Published: 18 January 2019

\begin{abstract}
The damage and fracture of fiber reinforced polymer composites are vital constraints in their applications. To understand the mechanism of damage of wood fiber (WF) reinforced high density polyethylene (HDPE) composites, we used waste WF and recycled HDPE (Re-HDPE) as the raw materials and prepared high-filled WF/Re-HDPE composites via extrusion. The damage and fracture mode and failure mechanism of the composites with different WF contents $(50 \%, 60 \%$, and $70 \%$ ) was studied under a three-point bending test by combining the acoustic emission (AE) technique and scanning electron microscope (SEM) analysis. The results show that AE technology can better assist in understanding the progress of damage and fracture process of WF/Re-HDPE composites, and determine the damage degree, damage accumulation, and damage mode. The damage and fracture process of the composites presents three main stages: the appearance of initial damage, damage accumulation, and destructive damage to fracture. The matrix deformation, fiber breakage, interface delamination, fiber-matrix debonding, fiber pull-out, and matrix cracking were the dominant modes for the damage of high-filled WF/Re-HDPE composites under bending load, and the AE signal changed in different damage stages and damage modes. In addition, the WF content and repeated loading had a significant influence on the composite's damage and fracture. The 50\% and $60 \% \mathrm{WF} /$ Re-HDPE composites produced irreversible damage when repeated load exceeded $75 \%$ of the maximum load, while $25 \%$ of the maximum load could cause irreversible damage for $70 \% \mathrm{WF} / \mathrm{Re}-\mathrm{HDPE}$ composites. The damage was accumulated owing to repeated loading and the mechanical properties of the composites were seriously affected.
\end{abstract}

Keywords: particle-reinforced composites; acoustic emission; damage mechanics; fracture; recycling

\section{Introduction}

Natural fiber composites depend on their inherent environmental and performance advantages and have become an alternative for replacing environmentally harmful synthetic materials, and hence, help control pollution problems [1]. Especially wood fiber (WF) reinforced high density polyethylene (HDPE) composites have been widely used in arenas such as construction, automotive, garden, interior decoration, and daily life [2,3]. However, in order to employ the wood textures and reduce the cost, the WF content of the composite needs to exceed $50 \%$ in the practical production, which causes a poor interface compatibility between the WF and HDPE. The poor interface results in micro cracks inside 
the WF/HDPE composites and expands, causing larger cracks or even breakage under sustained loading, resulting in material scrapping or life reduction.

Studies have shown that the WF/HDPE damage and fracture behavior are closely related to the fiber/matrix interface [4]. The damage and failure modes of fiber reinforced polymer composites are mainly divided into fiber pull-out, fiber breakage and delamination, matrix cracking, and fiber-matrix debonding [5-9]. However, it has been difficult to accurately and effectively distinguish the failure modes and understand the evolution of the damage mechanism of high-filled WF/HDPE by using the traditional evaluation methods and testing techniques. However, the damage process would produce an acoustic emission (AE) characteristic signal from occurrence to break. AE is one of the most reliable and well-established novel techniques in non-destructive testing, which can monitor and identify the stress wave signals of the composite from the microscopic deformation stage until the fracture process. Furthermore, the accumulation of damage during the deformation and failure process is monitored, the failure mechanism is identified, and the damage location and fracture modes are determined [10-14].

AE technique is often used to dynamically monitor the damage and failure process of fiber reinforced polymer composites and evaluate its properties (including fracture and mechanical properties), strength, and lifespan [5,8,9,15-18]. For instance, Dogossy and Czigany [19] combined the $\mathrm{AE}$ and scanning electron microscope (SEM) and analyzed the failure process of polyethylene (PE) composites filled with maize hull. The relationship between the amplitude and time suggested that there were three kinds of failure modes, namely matrix deformation (below $25 \mathrm{~dB}$ ), maize hull pull-out (26-40 dB), and maize hull breakage (over $41 \mathrm{~dB}$ ). In another study, the authors found similar results in delaminated glass fiber epoxy composites by combining the AE technology with digital image correlation [20]. However, four micromechanical deformation processes were determined in polypropylene/wood flour composites via $\mathrm{AE}$ and volume strain measurements analysis. The results conclude that the matrix polymer deforms mainly by shear yielding, fibers debonding initiated at extremely small deformations and stresses, which is followed by the fiber pull-out at an intermediate stress level, and the fracture of WF is the dominating deformation process [21]. Moreover, the number and amplitude range of AE signals caused by interface failure indicated that quality of the fiber-matrix interface plays a major role in the damage process of hemp fiber reinforced polypropylene composites [4]. The AE technology can also be used to evaluate the compatibility of the fiber-matrix interface in composites [22], and there is a clear correlation between the damage mechanism of fiber reinforced polymer composites and the AE parameters [23-25]. In addition, the AE results demonstrated the shifting of energy dissipation from matrix cracking to fiber pullout during the damage progression [11].

Although AE technology has been effectively employed in monitoring the damage process of fiber reinforced composite, there is still limited research on the damage and fracture process of high-filled WF/HDPE composites under three point bending. However, this material is often subjected to bending loads rather than tensile loads in daily application. Therefore, the authors prepared high-filled WF/HDPE composites with different fractions of WF $(50 \%, 60 \%$, and $70 \%)$, and combined $\mathrm{AE}$ technology with SEM to monitor the three-point bending loading process. The damage and failure behavior, such as damage and fracture characteristics, damage accumulation, damage location, and failure mechanism of the composites, were analyzed via parametric analysis, waveform analysis, and characteristic waveform analysis. This has crucial practical significance for enriching the non-destructive monitoring and performance evaluation methods of high-filled WF/HDPE composites.

\section{Materials and Methods}

\subsection{Materials}

Wood fiber (WF, Italian poplar (Populus euramevicana cv.'I-214'), particle size 40-80 mesh, the fiber aspect ratio is $4-7$, and the shape is irregular) was provided by the Jiangsu Siyang 
Wood Powder Factory, Siyang, China. Recycled high-density polyethylene (Re-HDPE, melt flow index $=1.23 \mathrm{~g} / 10 \mathrm{~min}$ at $190^{\circ} \mathrm{C}, 5 \mathrm{~kg}$ ) was obtained from the Yixing Zhangye Town Huahong Plastic Product Factory, Yixing, China. The commercial maleic anhydride grafted polyethylene (MA-g-PE, CMG9801) and stearic acid (HSt) were purchased from Shanghai Sunny Technology Co. Ltd. Shanghai, China and Shanghai Yanan Grease Chemical Co., Ltd., Shanghai, China, respectively. The MA-g-PE is a polymer interface coupling agent with strong reactivity. It helps to improve the compatibility between WF and Re-HDPE and the dispersibility of WF. Additionally, it plays a role as a bridge between compatibility and adhesion in composite systems. The HSt is a commonly used internal lubricant for wood-plastic products. It can effectively promote the plasticization of the Re-HDPE matrix and reduce the melt viscosity, improve the processing fluidity, and improve the surface finish of the product. The MA-g-PE and HSt used as the compatibilizer and lubricant in this experiment, respectively.

\subsection{Composite Preparation}

The WF was dried at $105{ }^{\circ} \mathrm{C}$ for $12 \mathrm{~h}$ to reach a moisture content of less than $1 \%$. Then, WF, Re-HDPE, and additives (MA-g-PE and HSt) were mixed uniformly in a high speed mixer (DQL-100, turbine blade and cast from 304 stainless steel; the maximum volume is $100 \mathrm{~L}$, Zhangjiagang Daqin Machinery Factory, Zhangjiagang, China). The homogeneous mixture was extruded through a one-step conical twin-screw extruder (model SJZ65, Shanghai Jwell Machinery Co.,Ltd., Shanghai, China) to prepare a highly-filled WF/Re-HDPE composite. The power of the main motor of the extruder was $37 \mathrm{KW}$, and the max output was $250 \mathrm{~kg} / \mathrm{h}$. The screw operated in counter-rotating mode and there were kneading blocks in the extruder head. The screw had a diameter of $65 / 132 \mathrm{~mm}$ and the aspect ratio was 25 . The extrusion process parameters were engine speed $=16-18 \mathrm{rpm}$, feeding speed $=8-10 \mathrm{rpm}$, and temperature $=150-155^{\circ} \mathrm{C}$. Three levels of composites $(50 \% \mathrm{WF} / \mathrm{Re}-\mathrm{HDPE}, 60 \% \mathrm{WF} / \mathrm{Re}-\mathrm{HDPE}$, and $70 \% \mathrm{WF} /$ Re-HDPE composites) were prepared, where the corresponding WF content was 50\%, $60 \%$, and $70 \%$ (weight percent (wt $\%$ )), and Re-HDPE content was $47 \%, 37 \%$, and $27 \%$ (weight percent $(w t \%))$, respectively. The content of MA-g-PE and HSt was $2 \%$ and $1 \%$ (weight percent (wt \%)) for each level. The prepared composite sheet was processed into a specimen with the size of $500 \mathrm{~mm}(\mathrm{~L}) \times$ $20 \mathrm{~mm}(\mathrm{~T}) \times 30 \mathrm{~mm}(\mathrm{R})$ using a precision push bench saw (CS70EB, Festool, Wendlingen, Germany).

\subsection{Characterization}

The specimen was kept in a landscape orientation and pressurized in a three-point bending mode using a universal testing machine (AUTOGRAPH AG-IC, Shimadzu, Kyoto, Japan) (shown in Figure 1). The span was $320 \mathrm{~mm}$, while the loading speed was $3 \mathrm{~mm} / \mathrm{min}$. The AE signals produced by the stressed specimen were collected using the AE signal acquisition system (PCI-2, Physical Acoustics Corporation (PAC), Princeton, New Jersey, USA). The PCI-2 AE acquisition system was divided into three parts: sensor, preamplifier, and high speed acquisition card. The sensor model was R15 while the resonant frequency was $150 \mathrm{kHz}$. The sensor was fixed on the surface of the specimen (the distance between the sensor and the center of the specimen was $50 \mathrm{~mm}$ ) and coupled with a coupling agent to ensure good contact with the specimen, and the detection threshold was $30 \mathrm{~dB}$. The AE signal was not collected when the amplitude was lower than the detection threshold ( $30 \mathrm{~dB})$, and gradually collected as the amplitude became higher than $30 \mathrm{~dB}$. The preamplifier uses PAC's 2/4/6 type to provide amplification of three gains of $20 / 40 / 60 \mathrm{~dB}$, and the gain in this experiment was chosen as $40 \mathrm{~dB}$. The sensor receives the AE signal, transmits it to the preamplifier, and then collects and records through the computer equipped with the AE acquisition card. The laboratory remained quiet and noise free at the test temperature of $25{ }^{\circ} \mathrm{C}$ and a relative humidity of $30-40 \%$ throughout the experiment.

For the repeated loading bending tests, the maximum load was set at $25 \%, 50 \%$, and $75 \%$ of the average maximum breaking load in the three-point bending test. The loading test was repeated three times and the specimen was broken during the fourth load. To determine the damage and fracture mode of the high-filled WF/Re-HDPE composite, the fracture surface of the specimen was observed using scanning electron microscopy (SEM, S-4860, Hitachi, Tokyo, Japan). The SEM operated at an 
accelerating voltage of $10.0 \mathrm{kV}$ and the fractured surfaces of the specimens were coated with a thin layer of gold prior to the SEM analysis.

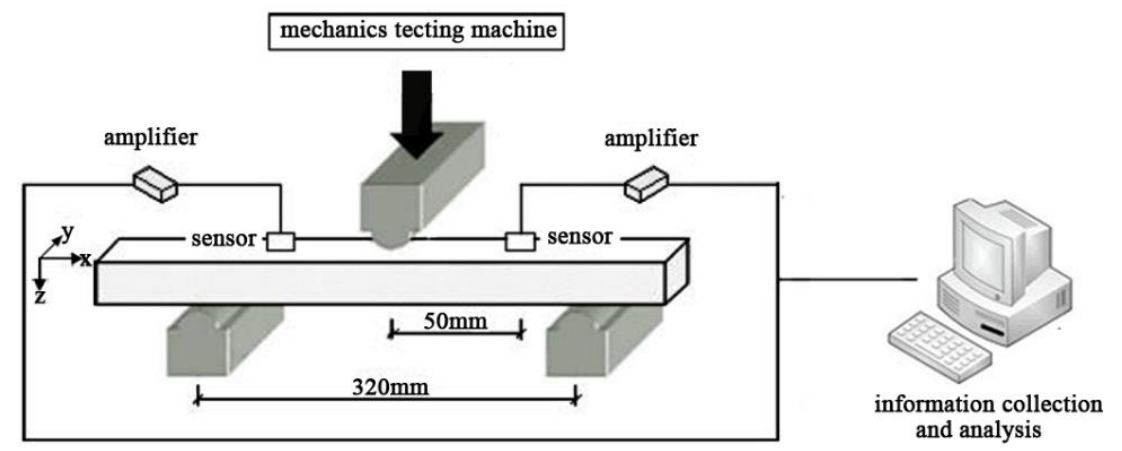

Figure 1. Schematic of the three-point bending test and the acoustic emission signal acquisition.

\section{Results and Discussion}

\subsection{AE Signal Analysis of Composites Damage and Fracture Mode}

Figure 2 shows that the AE accumulative energy varies with stress-strain during the three-point bending test. The bending procedure of high-filled WF/Re-HDPE composites consisted of three steps: line elastic deformation, nonlinearity deformation, and fracture. The line elastic deformation was short, while the nonlinearity deformation was long and showed a rapid decline when stress reached the maximum value. The SEM fracture analysis (see Figure 3) of the bending specimen shows that the damage modes were: matrix deformation, fiber breakage, interface delamination (fiber debonding), fiber pull-out, and matrix cracking. In addition, the fracture was relatively uniform and belonged to brittle failure [26,27].

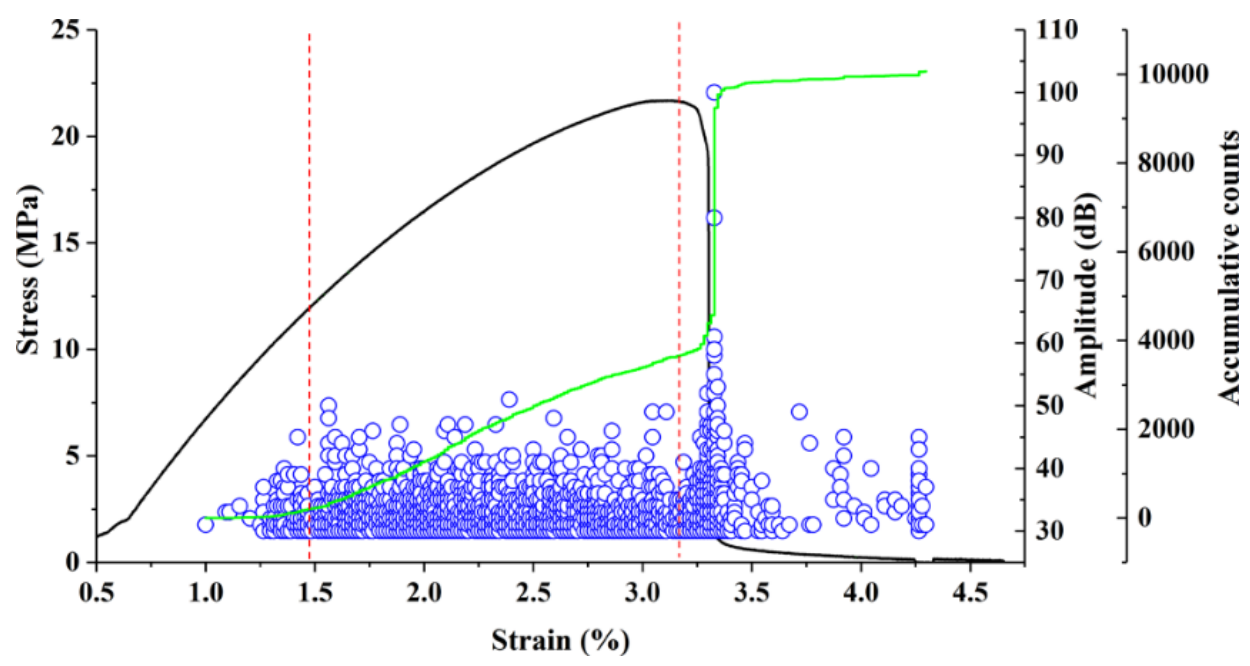

Figure 2. Acoustic emission (AE) accumulative counts vary with stress-strain during three-point bending test. The black curve represents stress-strain curve; the green curve represents $\mathrm{AE}$ accumulative counts; and the blue circle represents amplitude.

The study of the variation of AE signal parameters with stress-strain in the damage stage presents four stages: (1) initial damage, where there is a little AE signal generation, and a small number of $\mathrm{AE}$ signals appear at the late loading, indicating that the internal damage and AE event of the composite is extremely small, the released energy is minuscule at the initial stage; (2) slow damage growth, where the AE signal begins to show significant fluctuations, indicating that the damage in the composite begins to accumulate and grow as the stress increases, and the released energy due to damage begins 
to increase and tends to stabilize; (3) gradual intensification of damage, where the damage inside the composite is further increased with the increasing stress, and the AE event is gradually increased, indicating that the released energy is significantly increased; (4) sharp rise in damage, where both the $\mathrm{AE}$ event and the strain energy released by the fracture rise sharply.
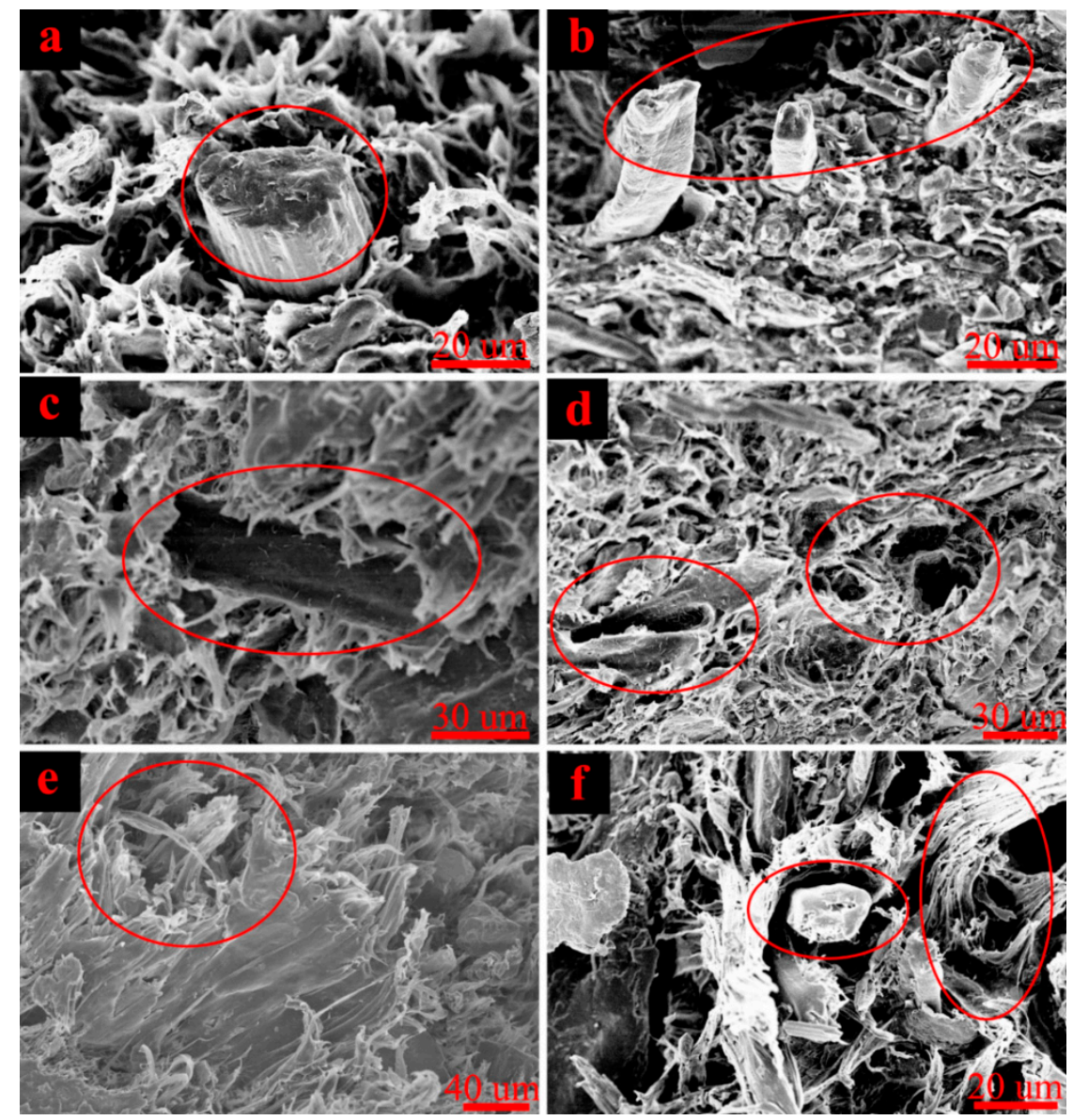

Figure 3. Scanning electron microscope (SEM (analysis of damage and fracture mode and characteristics $((\mathbf{a}, \mathbf{b})$-Fiber breakage; (c,d)_Fiber pull-out (interface friction); (e)-Matrix cracking; (f)-Fiber-matrix debonding (interface delamination) and matrix deformation).

A preliminary analysis of the pre-collected AE signals of the high-filled WF/Re-HDPE composite shows that frequencies were mainly within $400 \mathrm{KHz}$. Therefore, the sampling rate was set to $2 \mathrm{MHz}$ to ensure that the collected signals conformed to the Nyquist sampling theory and that the original signals were well recovered. For further study, the signal was decomposed and denoised by wavelet transform, and then reconstructed for each failure stage; the obtained five characteristic waveforms are shown in Figure 4. The five damage and fracture modes of the damage process were determined by combining the distribution of five AE characteristic waveforms and SEM fracture analysis. These damage modes had the following waveform characteristics. The initial AE signal produced in the bending test was type I, which was distributed throughout the AE process and was the dominant waveform, showing lower amplitude (general amplitude was lower than $40 \mathrm{~dB}$, average amplitude was $34.31 \mathrm{~dB}$ ) and energy. Type II began to appear sporadically in the initial nonlinearity deformation stage, gradually increased, and occurred throughout the damage and fracture process showing short rise time (generally less than $5 \mu$ s, average was $2.13 \mu \mathrm{s}$ ), high amplitude (generally above $50 \mathrm{~dB}$, average was $55.29 \mathrm{~dB}$ ), and high energy (average was $339.31 \times 10^{-9} \mathrm{~J}$ ); the average duration was $108.47 \mu$ s and ringing count (average was 13.70 times) was significantly higher than type I. Type III also began to appear in the nonlinearity deformation stage and later than type II, however, the occurrence frequency was higher 
than type II, especially in the later nonlinearity deformation and fracture stage, showing higher rise time (average was $40.43 \mu \mathrm{s}$ ) and high duration (average was $252.72 \mu \mathrm{s}$ ); the energy (average was $229.54 \times 10^{-9} \mathrm{~J}$ ) was slightly lower than the type II, general amplitude was higher than $40 \mathrm{~dB}$, average amplitude was $45.61 \mathrm{~dB}$, and ringing count (average was 24.96 times) was significantly higher than type II. Type IV primarily appeared with the interface delamination and fiber pull-out, showing high duration (average was $864.25 \mu \mathrm{s}$ ), high energy (average was $25.7 .12 \times 10^{-9} \mathrm{~J}$ ), high ringing count (average was 39.53 times), high amplitude (average was $48.36 \mathrm{~dB}$ ), and the average rise time was $75.925 \mu$ s. Type V appeared after Type III and mainly in the fracture, but less frequently, showing extremely high amplitude, energy, rise time, duration, and ringing counts, as shown in Table 1.
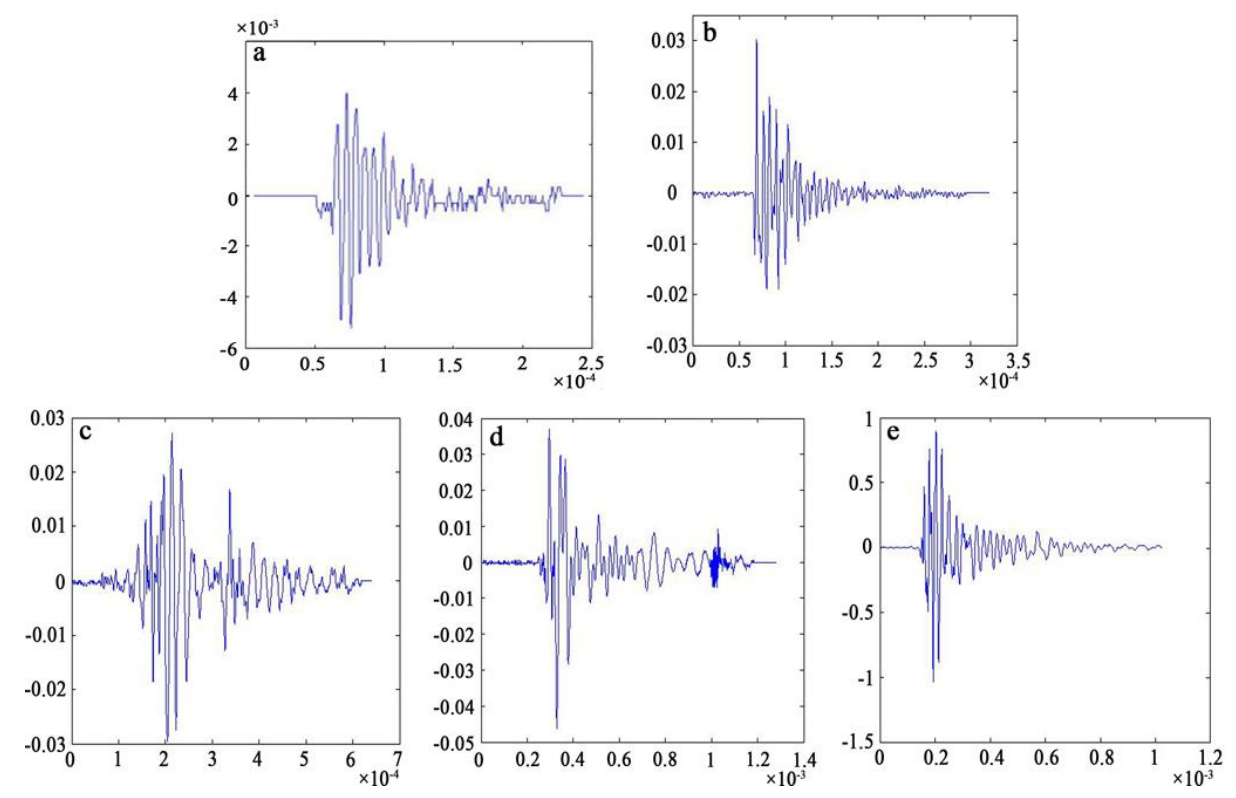

Figure 4. Five AE characteristic waveforms corresponding to the damage and fracture mode. (a) Type I (Matrix deformation); (b) Type II (Fiber breakage); (c) Type III (Interface delamination); (d) Type IV (Interface friction); and (e) Type V (Matrix cracking).

Table 1. Characteristics of AE signals corresponding to several damage modes.

\begin{tabular}{cccccc}
\hline Signal Type & Rise-Time/ $\boldsymbol{\mu s}$ & Duration/ $\boldsymbol{\mu s}$ & $\begin{array}{c}\text { Ringing } \\
\text { Counts }\end{array}$ & $\begin{array}{c}\text { Absolute } \\
\text { Energy } \mathbf{1 0}^{-\mathbf{9}} \mathbf{~ J}\end{array}$ & Amplitude/dB \\
\hline Matrix deformation & 8.95 & 48.63 & 5.34 & 76.46 & 34.31 \\
Fiber breakage & 2.13 & 108.47 & 13.70 & 339.31 & 55.29 \\
Interface delamination & 40.43 & 252.72 & 24.96 & 229.54 & 45.61 \\
Interface friction & 75.92 & 864.25 & 39.53 & 2577.12 & 48.36 \\
Matrix cracking & 577.84 & 2358.92 & 84.88 & 3479.46 & 61.38 \\
\hline
\end{tabular}

These results suggest that the damage and fracture process of WF/Re-HDPE composites under the three-point bending test can be summarized into three stages (Figure 5). In the first stage, the matrix of WF/Re-HDPE composites deformed under the bending load and varied AE signals (mostly at low amplitude and low energy) were induced by different matrix deformations. In the second stage, the matrix deformation accelerated as the loading continued. The fiber breakage and fiber debonding occurred in the meantime and cracks in the composites were generated and expanded. The Fiber debonding gradually increased in the later part of the second stage and was accompanied by fiber pull-out. The fiber breakage appeared earlier than the fiber debonding and the AE signal of fiber breakage mainly showed high amplitude and a short rise time. In the third stage, fiber debonding and fiber pull-out intensified with the increasing load which was accompanied by matrix cracking until the specimen fracture. The AE signal of interface friction generated due to fiber pull-out was mainly manifested as relatively low amplitude, whereas the matrix cracking manifested with a high 
amplitude. Moreover, the AE signals of interface friction and matrix cracking also showed high energy, long duration, long rise time, and large ringing counts.

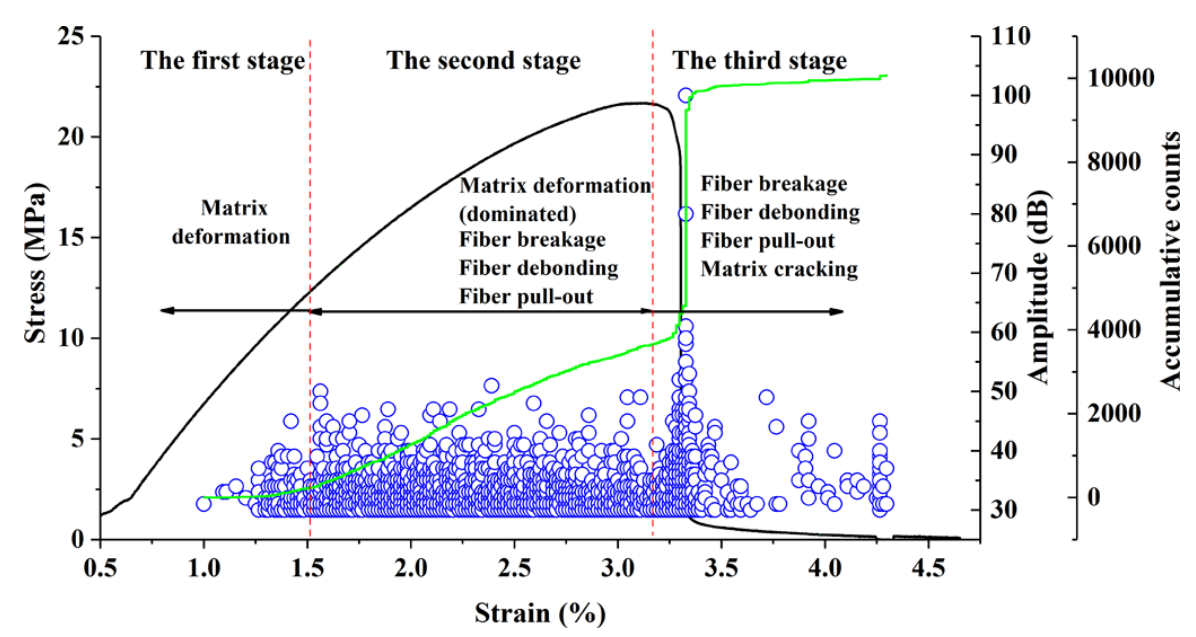

Figure 5. Distribution of damage and fracture stage and mode. The black curve represents stress-strain curve; the green curve represents AE accumulative counts; and the blue circle represents amplitude.

\subsection{Relationship between AE Signal and Stress-Strain of WF/Re-HDPE Composites}

Studies have shown that the AE parameters such as amplitude, ringing counts, accumulative ringing counts, and accumulative energy can reflect the evolution damage and fracture process of the WF/Re-HDPE composite $[4,28,29]$. Figure 6 shows the AE amplitude, ringing counts, and stress-strain curves of the $50 \%, 60 \%$, and $70 \% \mathrm{WF} / \mathrm{Re}-\mathrm{HDPE}$ composites. It can be seen that there were no $\mathrm{AE}$ events at the initial stage of loading; however, they gradually appeared with increasing stress-strain showing lower amplitude. With the further increase of stress-strain, AE events gradually increased and tended to be stable. Thereafter, as the stress increased to the vicinity of the maximum value, AE events suddenly increased and the amplitude increased rapidly (the maximum value was about $100 \mathrm{~dB}$ ). In addition, the AE events gradually decreased with an increasing WF content and the average amplitude significantly decreased; however, the maximum amplitude value was not significantly different. This was mainly caused by the enhanced fiber supporting effect on the matrix as the fiber content increased and the increased rigidity of WF/Re-HDPE composite. However, as the WF content increased, the agglomerated fiber results in a reduction in interfacial adhesion (as shown in Figure 7) [30]. The deformation and damage of the matrix was more serious, whereas the fiber breakage was decreased; hence, the amplitude and activity of AE decreased.

Figure $6 \mathrm{~d}-\mathrm{f}$ demonstrate that first, the AE ringing counts slowly increased with the increasing stress-strain, stabilized, and then suddenly increased (most did not exceed 100) as the stress reached the maximum to fracture. In addition, the ringing counts of the AE event was significantly reduced as the WF content increased. This is mainly because the matrix deformation and fiber debonding were the main damage modes during the damage process of WF/Re-HDPE composites. As the WF content increased, the dispersion of fibers in the matrix decreased and the mechanical interlocking of fiber-matrix reduced, which led to a reduction in the debonding of fiber-matrix during the damage process (as shown in Figure 7). Moreover, as the WF content increased, the ringing counts of the events with the ringing count above 100 had a tendency to decrease. This indicates that the signal impulse generated by the fracture of the WF/ Re-HDPE composite decreased with the increasing WF content. This was primarily because the distance between the macromolecular chains of the matrix increases with the increasing WF content and the bonding strength decreased, leading to a decrease in the signal impulse and duration of $\mathrm{AE}$ event. 

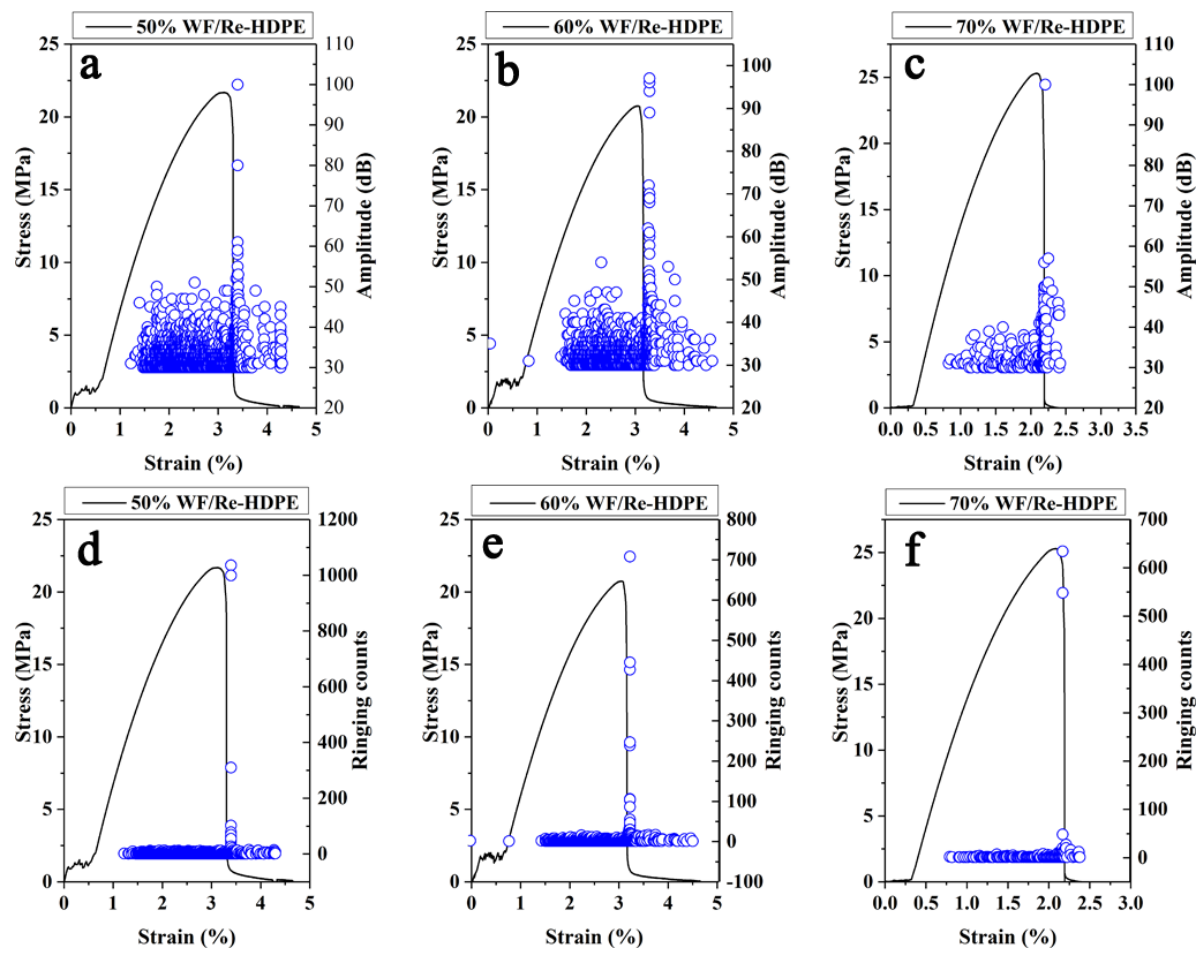

Figure 6. The AE amplitude, ringing counts, and stress-strain curves of wood fiber (WF)/recycled high density polyethylene (Re-HDPE) composites with different WF contents. The blue circle represents amplitude and ringing counts in $(\mathbf{a}-\mathbf{f})$, respectively.
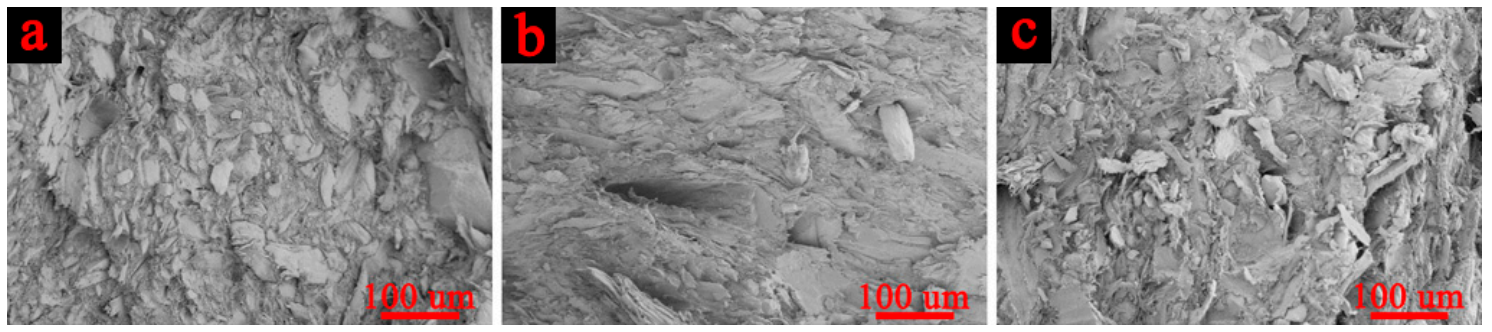

Figure 7. The interface morphology of WF/Re-HDPE composites with different WF contents ((a) $50 \%$ WF/Re-HDPE, (b) 60\% WF/Re-HDPE, and (c) 70\% WF /Re-HDPE).

Figure 8 shows the AE accumulative ringing counts, accumulative energy, and stress-strain curves of the $50 \%, 60 \%$, and $70 \% \mathrm{WF} /$ Re-HDPE composites. As the stress-strain increased, the accumulative ringing counts changed in four stages: slow increase in the first stage, rapid increase in the second stage, sudden increase in the third stage (fracture stage), and gentle increase in the fourth stage (fracture later period). Furthermore, the accumulative ringing counts increased with increasing WF content but the increase rate in the second stage became flat, whereas the fiber-matrix debonding was the main damage mode of composites in this stage. These results further confirm that the fiber-matrix debonding decreases with increasing WF content during the damage process.

According to Figure $8 \mathrm{~d}-\mathrm{f}$, the accumulative energy shows three major stages under the bending damage process. In the first stage, no energy was generated, as the stress-strain was low. The testing WF/Re-HDPE specimen only appeared to have undergone matrix deformation to generate potential energy. Then, the energy and damage slowly increased with the increasing stress-strain in the second stage and the energy of the AE signal suddenly increased in the third stage (fracture stage). This damage and fracture mode indicates that the WF/Re-HDPE composite is a brittle fracture material. Moreover, the total strain energy reduced during the damage and fracture process, however, the maximum stress was slightly increased. This is mainly because the rigidity of the composite increases as the WF content 
increased [30]. However, the debonding of fiber-matrix and the accumulative damage reduced with increasing WF content. Therefore, as the stress increased, the released strain energy reduced during the damage and fracture process.
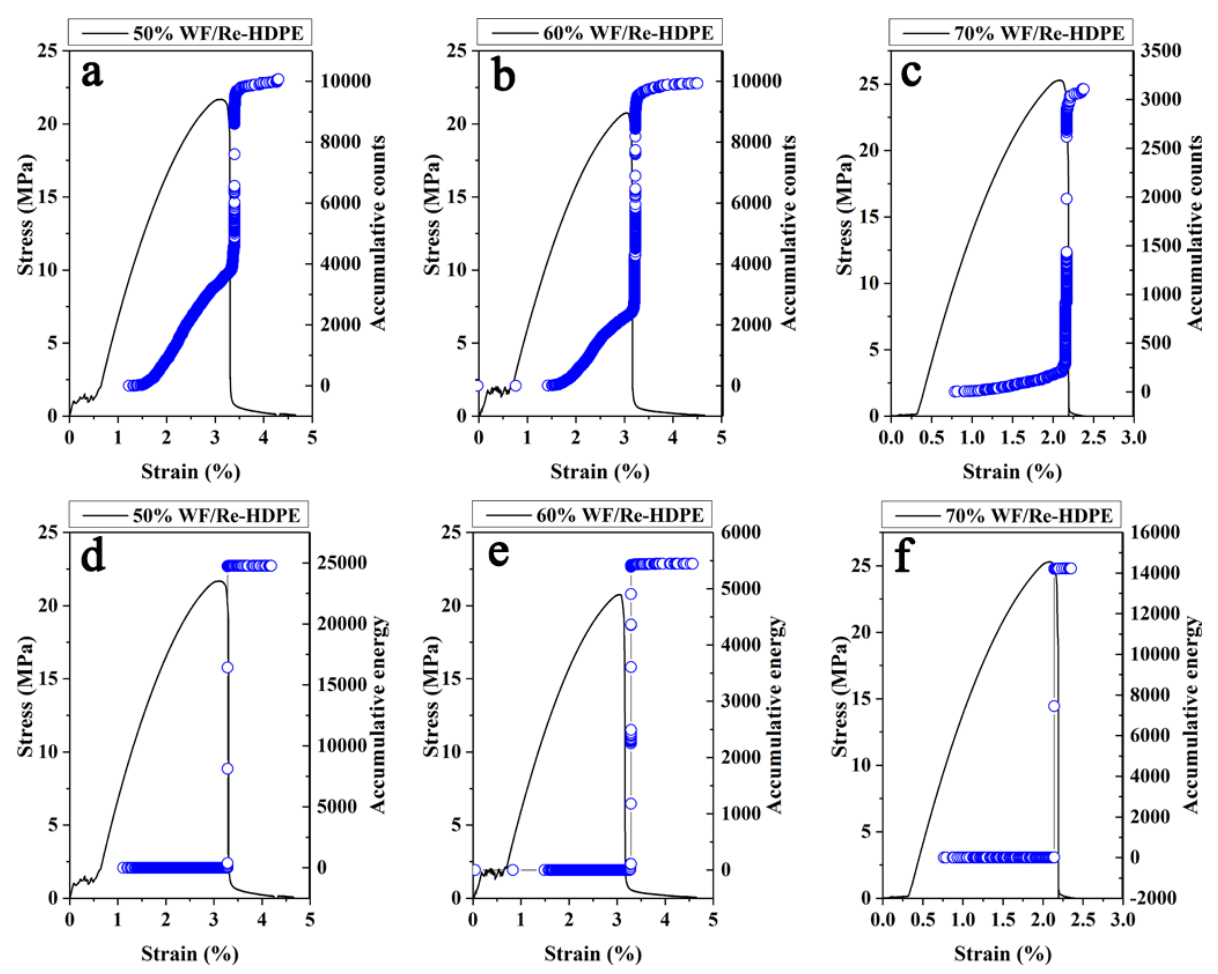

Figure 8. The AE accumulative ringing counts, accumulative energy, and stress-strain curve of WF/Re-HDPE composites with different WF content. The blue circle represents accumulative counts and accumulative energy in (a-f), respectively.

\subsection{AE Characteristics in Repeated Bending Loading Process}

When the material is loaded and no clear AE event occurs until the repeated load reaches the original maximum load, this AE irreversible property is called as the Kaiser effect [31-33]. On the other hand, if a clear AE event occurs before the repeated load reaches the original maximum load, it is called as the Felicity effect [34]. Felicity ratio refers to the ratio of the repeated load (load that produces the AE signal in repeated loading process) to the original maximum load. Better is the damage resistance of the composites, larger is the Felicity ratio; this has become the basis for the evaluation of the damage degree of polymer composites [34]. A Felicity ratio greater than 1 indicates that the Kaiser effect is true, and a value less than 1 indicates that the Felicity effect is true. A smaller Felicity ratio indicates more severe damage or more structural defects of the composites. A Felicity ratio less than 0.95 is often used as an important criterion for excessive acoustic emission in some composites [35].

The time variation of stress, $\mathrm{AE}$ amplitude, and accumulative ringing counts for $50 \%, 60 \%$, and $70 \% \mathrm{WF} /$ Re-HDPE composites is shown in Figures 9 and 10. The Felicity ratios of the WF/Re-HDPE composites are presented in Table 2. The Felicity ratios of WF/Re-HDPE composites under the first repeated loading were gradually reduced with the increasing WF content, which indicates that the accumulative damage memory capacity of the composites had an increasing trend. Among these, the Felicity ratio of the $50 \%$ and $60 \% \mathrm{WF} /$ Re-HDPE composite under the first repeated loading was greater than 1. These results indicate that these two levels of WF/Re-HDPE composites have a Kaiser effect in the initial stage of repeated loading. The damage was reversible for loads less than $25 \%$ of the maximum load; the composites had no memory for this damage. However, the Felicity ratio of the $70 \%$ WF/Re-HDPE composite under the first repeated loading was 0.93 (less than 0.95), which indicates that a load of less than $25 \%$ of the maximum load can cause irreversible damage to $70 \% \mathrm{WF} / \mathrm{Re}-\mathrm{HDPE}$ 
composites. Furthermore, the composites had a strong memory capacity for this damage and the mechanical properties of the composites were greatly affected by the damage. The Felicity ratio of these three WF/Re-HDPE composite levels under the second repeated loading was less than 1 , however, the Felicity ratio for 50\% and 60\% WF/Re-HDPE composites were 0.98 and 0.99 (greater than 0.95 ), respectively. This suggests that a load more than $50 \%$ of the maximum load could cause irreversible damage to the two levels of WF/Re-HDPE; however, the composites had a weaker memory for the damage. Then, the Felicity ratio of these three levels of WF/Re-HDPE composites gradually decreased with the increase in repeated loading times and stress, and the values were less than 0.95 . The irreversible damage of the composite was gradually increased, the memory capacity for the damage was gradually enhanced, and the repeated load had an increasing influence on the mechanical properties of the composites.
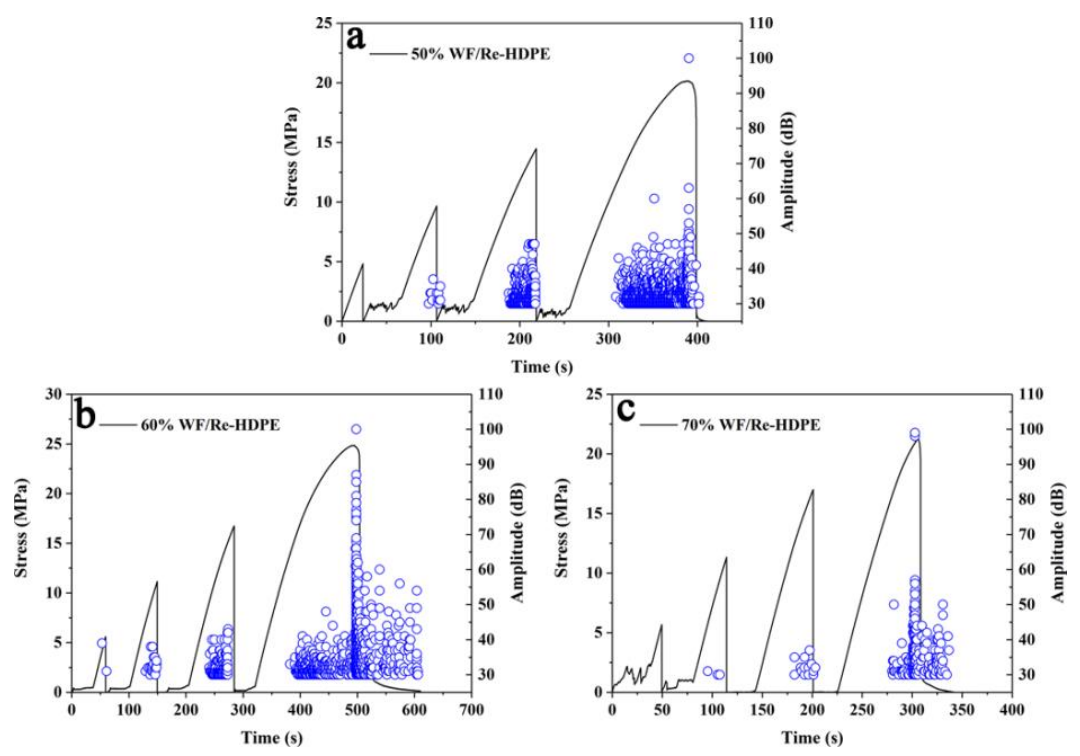

Figure 9. Time-strain curve and AE amplitude of WF/Re-HDPE composites with different WF content. The blue circle represents amplitude in Figure 9.

Moreover, with the increase in repeated loading times and stresses, the $\mathrm{AE}$ events of the WF/Re-HDPE composites gradually decreased, while the amplitude and the ringing counts gradually increased, indicating that the damage degree of WF/Re-HDPE composites was increased. When the loading was less than $75 \%$ of the maximum load, there was no AE signal for $50 \%$ and $60 \%$ WF/Re-HDPE composites until the repeated loading stress reached the last maximum loading stress. Thereafter, the signals appeared after stress exceeded the last maximum loading stress. In addition, the position of the AE signal was the same for the last loading process at the initial stage, which further confirms the Kaiser effect and the Felicity effect of the WF/Re-HDPE composites. The 70\% WF/Re-HDPE composite had an AE signal before the first repeated loading reached the last maximum strain, indicating that the composite had already produced a memory to the damage caused by the $25 \%$ loading and that the repeated loading had accumulated damage. In addition, Figure 10a-c also show a slope in the initial stage of accumulative ringing counts-time curve during the repeated loading process which is same as the slope in the last loading process, which further proves that the WF/Re-HDPE composites have a Felicity effect.

The above results indicate that both the Kaiser effect and the Felicity effect exist during the repeated loading of high-filled WF/Re-HDPE composites. The composites under lower repeated load mainly produced reversible damage at less WF content and had an irreversible damage at larger load or more repetitions, while the lower load could cause irreversible damage at high WF content. The $50 \%$ and $60 \% \mathrm{WF} / \mathrm{Re}-\mathrm{HDPE}$ composites produced irreversible damage when the load exceeded $75 \%$ of the maximum load, while the 70\% WF/Re-HDPE composites produced irreversible damage when the 
repeated load was less than $25 \%$ of the maximum load. However, these three levels of WF/Re-HDPE composites had memory for the damage caused by repeated loads. This may be because of the increase of WF content and the decrease of matrix, which resulted in the reduction of the fiber-matrix interface bonding strength. The fiber debonding occurred under a lower load and an irreversible damage was produced.
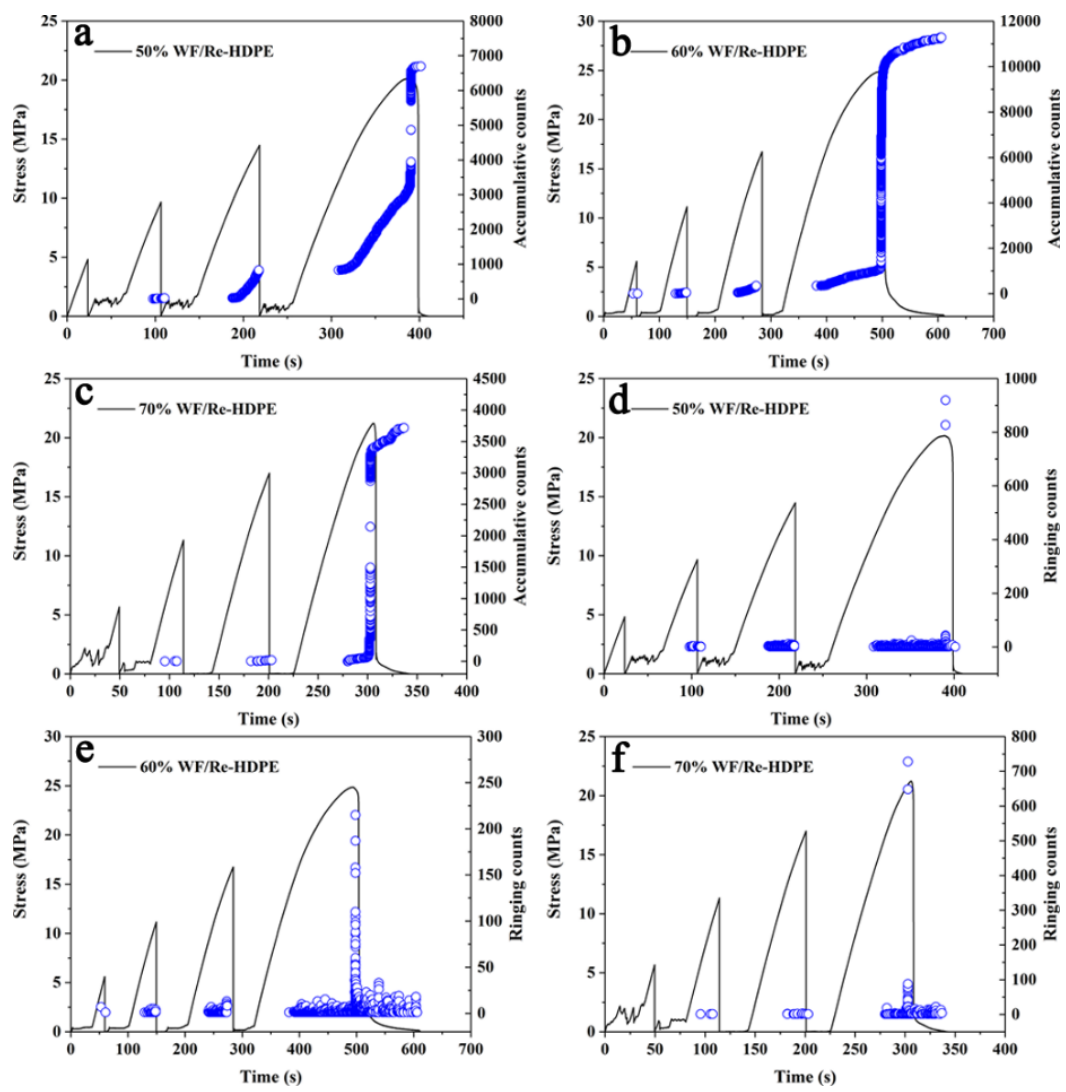

Figure 10. Time-strain curve, AE accumulative counts, and ringing counts of WF/Re-HDPE composites with different WF contents. The blue circle represents accumulative counts and ringing counts in (a-f), respectively.

Table 2. Felicity ratio of WF/Re-HDPE composites with different WF content.

\begin{tabular}{|c|c|c|c|c|}
\hline Sample & Loading Times & Maximum Strain\% & $\begin{array}{c}\text { Strain at AE Signals } \\
\text { Generated } \%\end{array}$ & Felicity Ratio \\
\hline 50\%WF/Re-HDPE & 1 & 0.37 & - & - \\
\hline $50 \% W F / R e-H D P E$ & 2 & 1.30 & 1.16 & 3.15 \\
\hline 50\%WF/Re-HDPE & 3 & 1.75 & 1.27 & 0.98 \\
\hline 50\%WF/Re-HDPE & 4 & 2.67 & 1.41 & 0.80 \\
\hline 60\%WF/Re-HDPE & 1 & 0.92 & 0.83 & - \\
\hline $60 \% W F /$ Re-HDPE & 2 & 1.41 & 1.09 & 1.18 \\
\hline 60\%WF/Re-HDPE & 3 & 2.10 & 1.40 & 0.99 \\
\hline $60 \% W F / R e-H D P E$ & 4 & 3.28 & 1.53 & 0.73 \\
\hline 70\%WF/Re-HDPE & 1 & 0.77 & - & - \\
\hline 70\%WF/Re-HDPE & 2 & 1.01 & 0.72 & 0.93 \\
\hline 70\%WF/Re-HDPE & 3 & 1.35 & 0.91 & 0.90 \\
\hline $70 \% W F /$ Re-HDPE & 4 & 1.64 & 1.08 & 0.80 \\
\hline
\end{tabular}

\section{Conclusions}

We combined the AE technique and SEM analysis to study the damage and fracture mode and mechanism of high-filled WF/Re-HDPE composites under a three-point bending test. The damage characteristics, damage location, and failure mechanism of the composites with different WF content 
were analyzed. The results showed that $\mathrm{AE}$ technology can assist in understanding the evolution of the damage and fracture process of WF/Re-HDPE composites and determine the damage degree, damage accumulation, and damage mode. The damage and fracture modes of high-filled WF/Re-HDPE composites under a three-point bending load were mainly matrix deformation, fiber breakage, interface delamination (fiber debonding), fiber pull-out, and matrix cracking. In addition, the damage and fracture process presents three main stages: the damage begins to occur in the first stage; less $\mathrm{AE}$ signal appears. Then, the damage accumulated in the second stage and the AE signal for different damage mode gradually increased. The third stage was the fracture stage, where the damage to the matrix and fiber was seriously exacerbated until the fracture as the AE signal showed a more pronounced change. Moreover, the Kaiser effect and the Felicity effect existed in the repeated loading of high-filled WF/Re-HDPE composites. The higher the WF content, the more severe the Felicity effect of the WF/Re-HDPE composites, the greater the accumulative damage caused by the repeated load, and the higher the influence on the mechanical properties of the composites. For WF/Re-HDPE composites with relatively low WF content, a low repetitive load mainly produced reversible damage, large load or more repetitions could cause irreversible damage, while the lower repeated loads could cause irreversible damage for WF/Re-HDPE composites with higher WF content.

Author Contributions: Y.G. and D.L. conceived, designed, and directed the project. Y.G. and S.Z. performed the experiments. Y.G., S.Z., and Y.C. supported the characterizations. Y.G. and S.Z. wrote the paper. All authors analyzed the data, discussed the results, and commented on the manuscript.

Funding: This work was funded by the Provincial Natural Science Foundation of Anhui [1708085MC56] and the Key Projects of Provincial Natural Science Foundation of Universities in Anhui [KJ2016A220].

Conflicts of Interest: The authors declare no conflict of interest.

\section{References}

1. Sanjay, M.R.; Madhu, P.; Jawaid, M.; Senthamaraikannan, P.; Senthil, S.; Pradeep, S. Characterization and properties of natural fiber polymer composites: A comprehensive review. J. Clean. Prod. 2018, 172, 566-581. [CrossRef]

2. Ayrilmis, N. Combined effects of boron and compatibilizer on dimensional stability and mechanical properties of wood/HDPE composites. Compos. Part B Eng. 2013, 44, 745-749. [CrossRef]

3. García, M.; Hidalgo, J.; Garmendia, I.; García-Jaca, J. Wood-plastics composites with better fire retardancy and durability performance. Compos. Part A 2009, 40, 1772-1776. [CrossRef]

4. Assarar, M.; Scida, D.; Zouari, W.; Saidane, E.H.; Ayad, R. Acoustic emission characterization of damage in short hemp-fiber-reinforced polypropylene composites. Polym. Compos. 2016, 37, 1101-1112. [CrossRef]

5. Zhuang, X.; Yan, X. Investigation of damage mechanisms in self-reinforced polyethylene composites by acoustic emission. Compos. Sci. Technol. 2006, 66, 444-449. [CrossRef]

6. Tekalur, S.A.; Shivakumar, K.; Shukla, A. Mechanical behavior and damage evolution in E-glass vinyl ester and carbon composites subjected to static and blast loads. Compos. Part B 2008, 39, 57-65. [CrossRef]

7. Malpot, A.; Touchard, F.; Bergamo, S. An investigation of the influence of moisture on fatigue damage mechanisms in a woven glass-fibre-reinforced PA66 composite using acoustic emission and infrared thermography. Compos. Part B Eng. 2017, 130, 11-20. [CrossRef]

8. Bohse, J. Acoustic emission characteristics of micro-failure processes in polymer blends and composites. Compos. Sci. Technol. 2000, 60, 1213-1226. [CrossRef]

9. Anuar, H.; Ahmad, S.; Rasid, R.; Surip, S.; Czigany, T.; Romhany, G. Essential work of fracture and acoustic emission study on TPNR composites reinforced by kenaf fiber. J. Compos. Mater. 2007, 41, 3035-3049. [CrossRef]

10. Saeedifar, M.; Najafabadi, M.A.; Zarouchas, D.; Toudeshky, H.H.; Jalalvand, M. Clustering of interlaminar and intralaminar damages in laminated composites under indentation loading using Acoustic Emission. Compos. Part B Eng. 2018, 144, 206-219. [CrossRef]

11. Nag-Chowdhury, S.; Bellégou, H.; Pillin, I.; Castro, M.; Longrais, P.; Feller, J. Crossed investigation of damage in composites with embedded quantum resistive strain sensors (sQRS), acoustic emission (AE) and digital image correlation (DIC). Compos. Sci. Technol. 2018, 160, 79-85. [CrossRef] 
12. Kravchuk, R.; Landis, E.N. Acoustic emission-based classification of energy dissipation mechanisms during fracture of fiber-reinforced ultra-high-performance concrete. Constr. Build. Mater. 2018, 176, 531-538. [CrossRef]

13. Gholizadeh, S.; Leman, Z.; Baharudin, B. A review of the application of acoustic emission technique in engineering. Struct. Eng. Mech. 2015, 54, 1075. [CrossRef]

14. De Rosa, I.M.; Santulli, C.; Sarasini, F. Acoustic emission for monitoring the mechanical behaviour of natural fibre composites: A literature review. Compos. Part A Appl. Sci. Manuf. 2009, 40, 1456-1469. [CrossRef]

15. Yu, F.-M.; Okabe, Y.; Wu, Q.; Shigeta, N. A novel method of identifying damage types in carbon fiber-reinforced plastic cross-ply laminates based on acoustic emission detection using a fiber-optic sensor. Compos. Sci. Technol. 2016, 135, 116-122. [CrossRef]

16. Habibi, M.; Lebrun, G.; Laperrière, L. Experimental characterization of short flax fiber mat composites: Tensile and flexural properties and damage analysis using acoustic emission. J. Mater. Sci. 2017, 52, 6567-6580. [CrossRef]

17. Czigány, T.; Marosfalvi, J.; Karger-Kocsis, J. An acoustic emission study of the temperature-dependent fracture behavior of polypropylene composites reinforced by continuous and discontinuous fiber mats. Compos. Sci. Technol. 2000, 60, 1203-1212. [CrossRef]

18. Carvelli, V.; D'Ettorre, A.; Lomov, S.V. Acoustic emission and damage mode correlation in textile reinforced PPS composites. Compos Struct. 2017, 163, 399-409. [CrossRef]

19. Dogossy, G.; Czigány, T. Failure mode characterization in maize hull filled polyethylene composites by acoustic emission. Polym. Test. 2006, 25, 353-357. [CrossRef]

20. Zhou, W.; Zhao, W.-Z.; Zhang, Y.-N.; Ding, Z.-J. Cluster analysis of acoustic emission signals and deformation measurement for delaminated glass fiber epoxy composites. Compos. Struct. 2018, 195, 349-358. [CrossRef]

21. Dányádi, L.; Renner, K.; Móczó, J.; Pukánszky, B. Wood flour filled polypropylene composites: Interfacial adhesion and micromechanical deformations. Polym. Eng. Sci. 2007, 47, 1246-1255. [CrossRef]

22. El-Abbassi, F.E.; Assarar, M.; Ayad, R.; Lamdouar, N. Effect of alkali treatment on Alfa fibre as reinforcement for polypropylene based eco-composites: Mechanical behaviour and water ageing. Compos. Struct. 2015, 133, 451-457. [CrossRef]

23. Marec, A.; Thomas, J.-H.; El Guerjouma, R. Damage characterization of polymer-based composite materials: Multivariable analysis and wavelet transform for clustering acoustic emission data. Mech. Syst. Signal Process. 2008, 22, 1441-1464. [CrossRef]

24. Li, W.; Ho, S.C.M.; Patil, D.; Song, G. Acoustic emission monitoring and finite element analysis of debonding in fiber-reinforced polymer rebar reinforced concrete. Struct. Health Monit. 2017, 16, 674-681. [CrossRef]

25. Li, D.; Shao, J.; Ou, J.; Wang, Y. Damage analysis of carbon nanofiber modified flax fiber composite by acoustic emission. Smart Struct. Syst. 2017, 19, 127-136. [CrossRef]

26. Subramanya, S.R.; Satyanarayana, K.G.; Pilar, B.S. Evaluation of Structural, Tensile and Thermal Properties of Banana Fibers. J. Nat. Fibers 2016, 14, 485-497.

27. Yue, L.I.; Zhang, R.; Yang, P.; Chen, Z.; Zongbei, H.E.; Xiong, X. Microstructure and mechanical properties of $2.5 \mathrm{D}$ curved shallow-crossing linking SiC_f/SiC composites fabricated by chemical vapor infiltration. Mater. Sci. Eng. Powder Metall. 2018, 23, 164-171.

28. Barré, S.; Benzeggagh, M.L. On the use of acoustic emission to investigate damage mechanisms in glass-fibre-reinforced polypropylene. NDT E Int. 1997, 52, 369-376. [CrossRef]

29. Kim, S.T.; Lee, Y.T. Characteristics of damage and fracture process of carbon fiber reinforced plastic under loading-unloading test by using AE method. Mater. Sci. Eng. A 1997, 234, 322-326. [CrossRef]

30. Dányádi, L.; Renner, K.; Szabo, Z.; Nagy, G.; Móczó, J.; Pukanszky, B. Wood flour filled PP composites: Adhesion, deformation, failure. Polym. Adv. Technol. 2006, 17, 967-974. [CrossRef]

31. Kaiser, J. Erkenntnisse und Folgerungen aus der Messung von Geräuschen bei Zugbeanspruchung von metallischen Werkstoffen. Arch. Für Das Eisenhüttenw. 1953, 24, 43-45. [CrossRef]

32. Kaiser, E. A Study of Acoustic Phenomena in Tensile Test. Ph.D. Dissertation, Technical University of Munich, München, Germany, 1950.

33. Lavrov, A. Kaiser effect observation in brittle rock cyclically loaded with different loading rates. Mech. Mater. 2001, 33, 669-677. [CrossRef] 
34. Li, C.; Nordlund, E. Experimental verification of the Kaiser effect in rocks. Rock Mech. Rock Eng. 1993, 26, 333-351. [CrossRef]

35. Adams, C.H. Recommended practice for acoustic emission testing of fiberglass tanks/vessels. In Proceedings of the 37th Annual Conference of the Society of Plastics Industry (SPI) Reinforced Plastics/Composites Institute, Washington, DC, USA, 11-15 January 1982. 